\title{
Repeated Sweeping of Membranes at Term Pregnancy as Method of Induction
}

\author{
Sonu K Batham ${ }^{1}$, Shaheen Anjum ${ }^{2}$
}

\begin{abstract}
Background: This study was aimed to determine the effectiveness of serial membranes sweeping in term pregnancy, and its effect on labor. Materials and methods: In this prospective study, 123 women with an uncomplicated pregnancy at 39 weeks or more gestation were recruited for the study; out of them, 38 were cases (serial sweeping group) and 85 were in the control (no sweeping group). The primary outcome measure was the occurrence of spontaneous labor and changes in Bishop's score after each sweeping. Other outcome measures included were interval of, occurrence of premature rupture of membranes, the total duration of active labor, mode of delivery, rate of cesarean section and its causes, and neonatal and maternal outcome.

Results: There were no statistically significant differences between the two groups regarding maternal age, parity, and Bishop's score at recruitment. The onset of labor was not significantly different in both groups $\{(6.82 \pm 1.967$ days $)(7.96 \pm 3.63$ days $)\}$ from the day of recruitment. A total of $27(75.0 \%)$ patients of the cases group delivered in the second week whereas there were 40 (47.05\%) patients of the control group. This showed a significant difference $(p<0.05)$, and five $(13.2 \%)$ patients went into postterm pregnancy, in comparison with $22(25.88 \%)$ patients in the control group. There was no significant difference regarding the mode of delivery and maternal and fetal outcomes in cases and controls. Conclusion: Frequent membrane sweeping is not having any significant effect in the mode of induction of labor.

Keywords: Induction of labor, Membrane sweeping, Postterm pregnancy, Spontaneous labor, Term pregnancy.

Journal of South Asian Federation of Obstetrics and Gynaecology (2021): 10.5005/jp-journals-10006-1938
\end{abstract}

\section{INTRODUCTION}

Sweeping of membranes was thought to be a mode of labor induction in the older era. The practice of sweeping membranes, also known as stripping of membranes, has decreased as a result of the introduction of new chemical methods and drugs, but now there is a demand to reintroduce stripping of membranes into modern obstetrics practices. Sweeping (or stripping) of membranes is defined as a digital separation of the chorioamniotic membranes from the lower uterine segment. Stripping of the membranes causes an increase in the activity of phospholipase $A_{2}$ and prostaglandin $F_{2 a}$ $\left(\mathrm{PGF}_{2 \mathrm{a}}\right)$ as well as causing mechanical dilation of the cervix, which releases prostaglandin metabolites in the maternal circulation and local prostaglandin production., ${ }^{1,2}$ At present, induction of labor is carried out approximately in 30\% of pregnancies, the common indications for induction are postdated pregnancy, hypertensive disorders, preterm rupture of membranes, and fetal demises. ${ }^{3}$ Postterm pregnancies are the pregnancies that extend up to 42 0/7 weeks of gestation or beyond. ${ }^{4}$ Postterm pregnancies are associated with increased risk of oligohydramnios, fetal distress, meconium aspiration syndrome, increased risk of operative intervention like cesarean deliveries, and instrumental deliveries. ${ }^{5}$ Postterm delivered babies are more likely to seek neonatal intensive care unit (NICU) care and greater neonatal mortality than full-term delivered babies. ${ }^{6}$ Sweeping of fetal membranes at term reduces the number of postterm pregnancies and chances of the formal induction of labor. ${ }^{7}$ Sweeping of membranes is rarely carried out by some practitioners, but there is a lack of agreement on its use and effectiveness, so we planned to evaluate the effectiveness of membranes sweeping to initiate labor and its effects on maternal and fetal outcomes.
${ }^{1}$ Department of Obstetrics and Gynaecology, Chhindwara Institute of Medical Sciences, Chhindwara, Madhya Pradesh, India

${ }^{2}$ Department of Obstetrics and Gynaecology, Jawaharlal Nehru Medical College and Hospital, Aligarh, Uttar Pradesh, India

Corresponding Author: Sonu K Batham, Department of Obstetrics and Gynaecology, Chhindwara Institute of Medical Sciences, Chhindwara, Madhya Pradesh, India, Phone: +91 8319317508, e-mail: bathamsonu007@gmail.com

How to cite this article: Batham SK, Anjum S. Repeated Sweeping of Membranes at Term Pregnancy as Method of Induction. J South Asian Feder Obst Gynae 2021;13(4):265-268.

Source of support: Nil

Conflict of interest: None

\section{Materials and Methods}

The study was performed at the Department of Obstetrics and Gyneacology, Jawaharlal Nehru Medical College and Hospital, AMU Aligarh, Uttar Pradesh, India. The study was approved by the ethical committee of the medical college. Written informed consent was obtained from all women who participated in the study. Women with uncomplicated pregnancies who were attending the antenatal clinic were enrolled in the study if they met the following criteria, low-risk pregnancies of confirmed 39 weeks or more and single fetus in cephalic presentation. Pregnancies with premature rupture of membranes, associated with medical complications, multifetal pregnancies, with previous two or more cesarean sections, and pregnancies contraindicated for vaginal delivery were excluded. The participants were divided into case and control groups.

(o) The Author(s). 2021 Open Access This article is distributed under the terms of the Creative Commons Attribution 4.0 International License (https://creativecommons. org/licenses/by-nc/4.0/), which permits unrestricted use, distribution, and non-commercial reproduction in any medium, provided you give appropriate credit to the original author(s) and the source, provide a link to the Creative Commons license, and indicate if changes were made. The Creative Commons Public Domain Dedication waiver (http://creativecommons.org/publicdomain/zero/1.0/) applies to the data made available in this article, unless otherwise stated. 


\section{Study Groups}

\section{Cases and Controls}

\section{Group Cases}

In this group, membrane sweeping was done three times, at 39 weeks of gestation, 39 weeks 4 days, and 40 weeks completed, and Bishop's score was assessed at every time and compared.

\section{Group Controls}

In this group, Bishop's score was assessed at 39 weeks of gestation by simple cervical examination, and no per-vaginum (PV) examination was done until indicated or the participant entered in active labor.

The aim of the study and procedure was explained to all participants at antenatal visits of 38 weeks around gestation. Participants were invited to out patient department (OPD) or labor room at their gestational age of 39 weeks completed. The membrane sweeping was done by using all aseptic precautions, in dorsal position, by introducing the index finger into the cervix and rotating the finger $360^{\circ}$ to separate the amniotic membranes from the lower uterine segment as much as possible. The participants of the control group had a gentle cervical examination to know Bishop's score at 39 weeks and no further PV examination was done until labor starts or indicated. Repeated membrane sweeping was done at 39 weeks 4 days and at 40 weeks completed in cases.

After sweeping, all participants were allowed to go home and explained about show, mild bleeding, and leaking PV and advised to count daily fetal body movements, and instructed to report in the labor room in case of any emergency.

Data were collected in terms of the total duration of pregnancy, Bishop's score on admission, the occurrence of spontaneous labor, duration of active labor, premature rupture of membranes, mode of delivery, the interval of onset of labor, need of oxytocics for induction or augmentation of labor and maternal and fetal infection, Apgar score, and admission in NICU.

The primary outcome was measured in terms of the occurrence of spontaneous labor in cases and controls, and the secondary outcome was measured in terms of maternal and neonatal outcomes in the study groups.

\section{Results}

The study was conducted with 123 participants, including 38 cases and 85 controls. Basic characteristics of the participants in both groups such as age, parity, ethnicity, and Bishop's score were collected similarly at the time of recruitment. Analyses of basic characteristics of the participants are listed in Table 1.

The onset of labor after membrane sweeping was calculated in terms of duration in days. For cases, the mean duration was

Table 1: Baseline characteristics

\begin{tabular}{lccc}
\hline & Cases & Controls & Significance \\
\hline Age & $24.6 \pm 4.1$ & $23.8 \pm 3.7$ & NS \\
Primigravidae & 18 & 38 & $p=0.895$ \\
Multigravidae & 20 & 47 & \\
Booked & 36 & 80 & $p=0.773$ \\
Unregistered & 2 & 5 & \\
$\begin{array}{l}\text { Bishop's score at } \\
\text { recruitment }\end{array}$ & $3.39 \pm 1.0$ & $3.59 \pm 0.95$ & $t=1.1$ \\
\hline
\end{tabular}

$6.82 \pm 1.967$ days, and in this group, only 22 women went in spontaneous labor. In the control group, the mean duration was from 39 weeks until the onset of labor was $7.96 \pm 3.630$ days; in this group, 57 out of 85 women went in spontaneous labor. After comparing cases with controls, we found no significant difference (Table 2).

Mean Bishop's score at the initiation of labor was $(6.95 \pm 1.961$ and $7.00 \pm 2.19$ ) for cases and control, respectively. The mean duration of active labor was $7.15 \pm 2.19$ hours for cases and $6.56 \pm 2.28$ hours for control. On comparing, we found no significant difference \{paired $t$-test $(t=1.1)\}$.

In cases, 26/38 (68.4\%) patients delivered vaginally and 12/38 (31.6\%) patients delivered by cesarean section. In the control group, 64/85 (75.3\%) patients delivered vaginally and 20/85 (23.5\%) patients delivered by cesarean section, and 01/85 (0.8\%) patients delivered by forceps. The $p$-value $(p=0.530)$ suggested that there was no significant difference regarding mode of delivery.

In cases, $13 / 38$ (34.2\%) patients needed oxytocin infusion, $05 / 38(13.2 \%)$ patients needed early artificial rupture of membranes (ARM )to augment the labor, and 20/38 (52.6\%) patients did not need any augmentation. In the control group, 28/85 (32.9\%) patients needed oxytocin infusion, 11/85 (12.9\%) patients needed early ARM to augment the labor, and $46 / 85$ (54.1\%) patients did not need any augmentation. The $p$-value ( $p=0.988$ ) was suggestive of no significant difference.

For the cases group, the mean gestational age at delivery was $40.31 \pm 0.47$ weeks, whereas for controls, the mean gestational age at delivery was $40.42 \pm 0.65$ weeks. After a comparison between groups $(t=1.0)$, there was no significant difference between gestational ages at delivery.

Total cesarean sections due to non progress of labour (NPOL) were 12 in number. Out of them, three $(7.9 \%)$ were in cases and eight $(9.4 \%)$ were in the control group. The total number of cesarean sections due to fetal distress was 31 (16.9\%). Out of them, 9 (23.7\%) were in the cases group, and $12(14.1 \%)$ were in the control group. The incidence of cesarean section due to fetal distress was statistically similar in both groups.

There was no significant effect of sweeping on the occurrence of premature rupture of membranes (PROM) though the incidence of PROM was more in the case group $(p=1.43)$.

In the cases group, $6(15.18 \%)$ patients delivered in the first week compared to $23(27.05 \%)$ patients in the control group ( $p=1.85$ ); the difference was not significant. Twenty-seven out of 38 (75.0\%) patients in the cases group delivered at the gestational age between 40 weeks and 40 weeks 6 days, whereas 40 out of $85(47.05 \%)$ patients delivered at the same gestational age in the control group. This showed a significant difference $(p<0.05)$. In cases group, 5 (13.2\%) patients went into postterm pregnancy, in comparison with $22(25.88 \%)$ in the control group; the difference was insignificant ( $p=2.5$ ) (Table 3 ).

There was a significant increase in Bishop's score after the first attempt (at 39 weeks) of sweeping $\{(3.37 \pm 1.025)$ to $(4.76 \pm 1.384)\}(t=4.9)$ in the cases group. On the second attempt of sweeping (at 39 weeks 4 days), there was no significant increase in the mean Bishop's score $\{(4.65 \pm 1.253)$ to $(5.23 \pm 1.627)(t=1.6)\}$ (Table 4).

There was no difference regarding Apgar score in cases and control groups. For all patients, Apgar score at 5 minutes was 9/10. There was no prolonged NICU admission in cases and control groups. There was no prolonged antibiotics administration in cases and control groups. There was no maternal death in the study groups. 
Table 2: Primary study outcomes

\begin{tabular}{|c|c|c|c|c|c|}
\hline & \multicolumn{2}{|c|}{ Cases } & \multicolumn{2}{|c|}{ Controls } & Significance \\
\hline $\begin{array}{l}\text { The onset of spontaneous } \\
\text { labor }\end{array}$ & \multicolumn{2}{|c|}{$22(57.9 \%)$} & \multicolumn{2}{|c|}{$57(67.1 \%)$} & $p=0.238$ \\
\hline Need for induction & \multicolumn{2}{|c|}{$16(42.1 \%)$} & \multicolumn{2}{|c|}{$28(32.9 \%)$} & \\
\hline $\begin{array}{l}\text { Duration of active labor } \\
\text { (mean } \pm S D \text { ) (hours) }\end{array}$ & \multicolumn{2}{|c|}{$7.15 \pm 2.19(26)$} & \multicolumn{2}{|c|}{$6.56 \pm 2.28(65)$} & $t=1.1(\mathrm{NS})$ \\
\hline $\begin{array}{l}\text { Recruitment to delivery } \\
\text { interval in days }\end{array}$ & \multicolumn{2}{|c|}{$6.82 \pm 1.967$} & \multicolumn{2}{|c|}{$7.96 \pm 3.630$} & $t=1.8(\mathrm{NS})$ \\
\hline $\begin{array}{l}\text { Bishop's score at initiation } \\
\text { of labor (mean } \pm \text { SD) }\end{array}$ & \multicolumn{2}{|c|}{$6.95 \pm 1.961$} & \multicolumn{2}{|c|}{$7.00 \pm 2.19$} & $t=0.09$ (NS) \\
\hline $\begin{array}{l}\text { Gestational age at time of } \\
\text { delivery (weeks } \pm \text { SD) }\end{array}$ & \multicolumn{2}{|c|}{$40.31 \pm 0.47$} & \multicolumn{2}{|c|}{$40.42 \pm 0.65$} & $t=1.0(\mathrm{NS})$ \\
\hline PROM & \multicolumn{2}{|c|}{$08(21.1 \%)$} & \multicolumn{2}{|c|}{$10(11.8 \%)$} & $p=0.143(\mathrm{NS})$ \\
\hline \multirow[t]{3}{*}{ Need for augmentation } & Oxytocin & $13(34.2 \%)$ & Oxytocin & $28(32.9 \%)$ & $p=0.988(\mathrm{NS})$ \\
\hline & ARM & $05(13.2 \%)$ & ARM & $11(12.9 \%)$ & \\
\hline & No Aug. & $20(52.6 \%)$ & No Aug. & $46(54.1 \%)$ & \\
\hline \multirow[t]{3}{*}{ Mode of delivery } & Vaginal & $26(68.4 \%)$ & Vaginal & $64(75.3 \%)$ & $p=0.530(\mathrm{NS})$ \\
\hline & Cesarean & $12(31.6 \%)$ & Cesarean & $20(23.5 \%)$ & \\
\hline & Instrumental & 0.0 & Instrumental & $01(0.8 \%)$ & \\
\hline \multirow{2}{*}{$\begin{array}{l}\text { Indication for cesarean } \\
\text { section }\end{array}$} & NPOL & $03(7.9 \%)$ & NPOL & $08(9.4 \%)$ & $p=0.179(\mathrm{NS})$ \\
\hline & Fetal distr & 09 (23.7\%) & Fetal distr & $12(14.1 \%)$ & \\
\hline
\end{tabular}

Table 3: Number of deliveries at weekly interval

\begin{tabular}{lccccc}
\hline & \multicolumn{2}{c}{ Cases } & & \multicolumn{2}{c}{ Control group } \\
\cline { 2 - 3 } \cline { 5 - 6 } Gestational age in weeks & $\begin{array}{c}\text { No. of } \\
\text { deliveries }\end{array}$ & & & No. of & \\
deliveries & $\%$ \\
\hline 39 weeks-39 weeks 6 days & 06 & 15.18 & & 23 & 27.05 \\
40 weeks-40 weeks 6 days & 27 & 75.0 & & 40 & 47.05 \\
$\geq 41$ weeks & 05 & 13.88 & & 22 & 25.88 \\
Total & 38 & 100 & & 85 & 100 \\
\hline
\end{tabular}

First week -39 weeks-39 weeks 6 days, cases-control $-p=1.85$ (NS); Second week -40 weeks -40 weeks 6 days, cases-control $p<0.05$; Postterm preg- $\geq 41$ weeks, cases-control $X^{2}=2.5$ (NS)

Table 4: Comparison of Bishop's score after each attempt of sweeping in cases

\begin{tabular}{lcccc}
\hline Gestational age & No. of cases & $\begin{array}{c}\text { Mean Bishop's } \\
\text { score }\end{array}$ & SD & t-test \\
\hline $39+0$ weeks & 38 & 3.37 & 1.025 & 4.9 \\
$39+4$ weeks & 38 & 4.76 & 1.384 & \\
$39+4$ weeks & 31 & 4.65 & 1.253 & 1.6 \\
$40+0$ weeks & 31 & 5.23 & 1.627 & \\
\hline
\end{tabular}

\section{Discussion}

Several clinical trials over membrane sweeping have variable results and conclusions regarding the efficacy of sweeping of membranes as a mode of labor induction. Routine use of sweeping of membranes from 38 weeks of gestation onward does not seem to produce clinically important benefits when used as a mode of induction. ${ }^{8}$ The World Health Organization (WHO) recommends the sweeping of membranes for reducing formal induction of labor. ${ }^{9}$ Sweeping of membranes was found to be a safe and effective procedure in reducing the incidence of postmature pregnancies and labor induction rate. ${ }^{10}$ We carried out this study to check the efficacy of sweeping and its effects on labor, duration of pregnancy, and adverse effects on maternal and fetal outcomes.

In our study, we compared three times sweeping with no sweeping. Still, there is no study to compare such repeated frequent sweepings' results. In our study, we did not find any advantages of frequent repeated sweeping in the effect of starting spontaneous labor. Most of the other studies suggest that repeated sweepings have advantages to start spontaneous labor and reduce the chances of postterm pregnancies. In our study, there was no significant effect of repeated frequent sweeping in achieving spontaneous labor or reducing the need for formal induction. Jeewantha et al. concluded in their study that twice sweeping of membranes over single sweeping was found to be an effective and safe method in reducing the need for formal induction. ${ }^{11}$ The similar positive result was found by Finucane et al. that sweeping of membranes may be effective in achieving a spontaneous onset of labor when compared to expectant management. ${ }^{12}$ ZamZami et al. reported that most of the women entered in spontaneous labor in the study group (90 vs $75 \%$ ), and most of them required only single sweeping while performed weekly sweeping; they could not found any exact effect of repeated membrane sweeping. ${ }^{13}$ Putnam et al. in their randomized trial concluded that frequent membrane sweeping does not influence the incidence of undelivered at 41 weeks of pregnancy; they also stated that Bishop's score at 39 weeks is the important factor as a predictor of the duration of pregnancy. ${ }^{14}$

In our study, we found a significant increase in Bishop's score after first sweeping that is correlating with Putnam et al. that repeated membrane sweeping does not influence the incidence of postterm pregnancy and maybe inline of suggestive of more effectiveness of single membranes sweeping over frequent 
sweepings. We also observed that the maximum number of patients who delivered in cases were in the subgroup of 40-41 weeks of gestation, which is in favor of sweeping works at later gestational age than preterm. ${ }^{7,11}$

Secondary outcomes were similar to maximum literature like duration of active labor, mode of deliveries, and various indications for cesarean section. The rate of PROM was comparable to other previous studies. ${ }^{15}$

We did not find any effect on Bishop's score at the initiation of labor, mode of delivery, duration of labor, and need of oxytocics for augmenting the labor process. We also included the participants having a history of previous one cesarean section but not calculated them separately as having very fewer numbers, Mukhri Hamdan et al. found no significant effect on the onset of labor of serial membranes sweeping at term in term pregnant women planned for vaginal birth after cesarean delivery (VBAC). ${ }^{16}$

\section{ConcLusion}

In our study, we did not find any significant effects of very frequent repeated sweeping. But the frequent membrane sweeping does not adversely affect the labor process and maternal and fetal health outcomes, so it is found to be a safe procedure. The limitation of our study was the smaller size of the case group because some participants did not report in the follow-up. We recommend a larger study for the sweeping of membranes.

\section{References}

1. Tenore JL. Methods for cervical ripening and induction of labor. Am Fam Physician 2003;67(10):2123-2128. PMID: 12776961.

2. Adair CD. Nonpharmacologic approaches to cervical priming and labor induction. Clin Obstet Gynecol 2000;43(3):447-454. DOI: 10.1097/00003081-200009000-00005.

3. Chawla S, Singh SK, Saraswat M, et al. Induction of labor: our experience. J Mar Med Soc 2017;19(2):96-98. DOI: 10.4103/jmms.jmms_51_17.

4. ACOG Committee Opinion No 579: definition of term pregnancy. Obstet Gynecol 2013;122(5):1139-1140. DOI: 10.1097/01. AOG.0000437385.88715.4a. PMID: 24150030.

5. Galal M, Symonds I, Murray H, et al. Postterm pregnancy. Facts Views Vis Obgyn 2012;4(3):175-187. PMID: 24753906; PMCID: PMC3991404.
6. Bruckner TA, Cheng YW, Caughey AB. Increased neonatal mortality among normal-weight births beyond 41 weeks of gestation in California. Am J Obstet Gynecol 2008;199(4):421.e1-421.e7. DOI: 10.1016/j.ajog.2008.05.015. PMID: 18639211.

7. Boulvain M, Stan C, Irion O. Membrane sweeping for induction of labour. Cochrane Database Syst Rev 2005;2005(1):CD000451. DOI: 10.1002/14651858.CD000451.pub2 [Update in: Cochrane Database Syst Rev 2020;2:CD000451. PMID: 15674873; PMCID: PMC7032890].

8. Boulvain M, Irion O. Stripping/sweeping the membranes for inducing labour or preventing post-term pregnancy. Cochrane Database Syst Rev 2000;(2):CD000451. DOI: 10.1002/14651858.CD000451 [Update in: Cochrane Database Syst Rev 2001;(2):CD000451. PMID: 10796204].

9. WHO Reproductive Health Library. WHO recommendation on sweeping of membranes for reducing formal induction of labour. Geneva: World Health Organization, The WHO Reproductive Health Library; 2011.

10. Allott $\mathrm{HA}$, Palmer $\mathrm{CR}$. Sweeping the membranes: a valid procedure in stimulating the onset of labour? Br J Obstet Gynaecol 1993;100(10): 898-903. DOI: 10.1111/j.1471-0528.1993.tb15103.x. PMID: 8217970.

11. Jeewantha RD, JayathilakeWMBG, Talagala IA, etal. The effectiveness of twice versus once-only membrane sweeping among uncomplicated primi gravidae at 40 weeks of gestation-a randomized controlled trial. Sri Lanka J Obstet Gynaecol 2018;40(4):78-84. DOI: 10.4038/ sljog.v40i4.7869.

12. Finucane EM, Murphy DJ, Biesty LM, et al. Membrane sweeping for induction of labour. Cochrane Database Syst Rev 2020;2(2):CD000451. DOI: 10.1002/14651858.CD000451.pub3. PMID: 32103497; PMCID: PMC7044809.

13. Zamzami T, Al Senani N. The efficacy of membrane sweeping at term and effect on the duration of pregnancy: a randomized controlled trial. J Clin Gynecol Obstet N Am 2014;3(1):30-34. DOI: 10.14740/ jcgo225w.

14. Putnam K, Magann EF, Doherty DA, et al. Randomized clinical trial evaluating the frequency of membrane sweeping with an unfavorable cervix at 39 weeks. Int J Women's Health 2011;3:287-294. DOI: 10.2147/IJWH.S23436.

15. Saichandran S, Arun A, Samal S, et al. Efficacy and safety of serial membrane sweeping to prevent post term pregnancy: a randomised study. Int J Reprod Contracept Obstet Gynecol 2017;4(6):1882-1886. DOI: 10.18203/2320-1770.ijrcog20151279. ISSN 2320-1789.

16. Hamdan M, Sidhu K, Sabir N, et al. Serial membrane sweeping at term in planned vaginal birth after cesarean: a randomized controlled trial. Obstet Gynecol 2009;114(4):745-751. DOI: 10.1097/ AOG.0b013e3181b8fa00. PMID: 19888030. 